\title{
Windsat Validation Using SeaWinds, Windrad and Polscat Mesaurements
}

\author{
Simon H. Yueh, William J. Wilson, Steve Dinardo, and S. Vincent Hsiao \\ Jet Propulsion Laboratory \\ California Institute of Technology \\ Pasadena, California, USA \\ Simon.Yueh@jpl.nasa.gov
}

\begin{abstract}
Global mapping of near surface ocean wind vectors is crucial for many oceanographic and atmospheric studies. The US Navy together with the National Polar Orbiting Environmental Satellite System (NPOESS) launched the WindSat with multi-frequency polarimetric radiometers in January 2003 to demonstrate the passive polarimetry for large spatial coverage of ocean surface wind vector measurements from space. We derived the geophysical model function (GMF) for Windsat polarimetric brightness temperature measurements using six months of matchup dataset. The Windsat GMF was compared with the aircraft radiometer and radar measurements and the SeaWinds scatterometer winds with good agreement up to about $20 \mathrm{~m} / \mathrm{s}$ wind speed.
\end{abstract}

Keywords: Sea surface wind; microwave polarimetric radiometer

\section{INTRODUCTION}

The near surface ocean wind, generating the momentum flux affecting ocean circulation and mixing, is the key driving force in air-sea interaction processes. Global mapping of near surface ocean wind vectors is crucial for many oceanographic and atmospheric studies. To obtain this key measurement, scientific satellite scatterometers, including the NASA scatterometer (NSCAT), the SeaWinds scatteroemeter on the QuikSCAT spacecraft and the SeaWinds scatterometer on the Japanese Advanced Earth Observation System satellite, were launched to acquire a time-series of global ocean surface winds.

With the potential of being an alternate technique to active microwave radar, the passive microwave polarimetry for surface wind vector measurements has been investigated in the range of wind speed from 3 to $15 \mathrm{~m} / \mathrm{s}$ by many aircraft field campaigns [1-8]. Based on these experimental observations, the US Navy together with the National Polar Orbiting Environmental Satellite System (NPOESS) launched the WindSat with multi-frequency polarimetric radiometers in January 2003 to demonstrate the passive polarimetry for large spatial coverage of ocean surface wind vector measurements from space.

The first step toward the retrieval of ocean surface winds from Windsat brightness temperatures is to develop a geophysical model function, relating the polarimetric brightness temperatures to ocean surface wind speed and direction. In this article we present the 18 and $37 \mathrm{GHz}$ GMF derived from the Windsat data and the validation results using observations from aircraft instruments and SeaWinds scatterometer.

\section{WINDSAT GEOPHYSICAL MODEL FUNCTION}

We have developed the polarimetric geophysical model function for WINDSAT using six months of WINDSAT data and the collocated Global Data Assimilation System (GDAS) winds. The collocated data set covers September 2003 through February 2004. To remove the impact of atmosphere, we applied a technique that we developed in the past to estimate the atmospheric attenuation from the data set itself [5]. The attenuation is estimated using the vertically and horizontally polarized brightness temperatures. The estimates from both polarizations are very consistent, indicative of the relative consistency of brightness temperature measurements for both polarizations. From the attenuation estimates, we correct the impact of atmosphere on the third (U) and fourth (V) Stokes parameter measurements from WINDSAT. This technique enables us to use essentially all the data, except for rainy conditions, to develop the geophysical model function.

We binned the corrected $\mathrm{U}$ and $\mathrm{V}$ data as a function of the GDAS wind speed at $1-\mathrm{m} / \mathrm{s}$ step and wind direction at 10 degree step. The $\mathrm{U}$ data at 18 and $37 \mathrm{GHz}$ and $\mathrm{V}$ data at 18 $\mathrm{GHz}$ show clear sinusoidal dependence on wind direction for wind speed above $5 \mathrm{~m} / \mathrm{s}$.

To derive the geophysical model function for the WINDSAT measurements, we fit the $U$ and $\mathrm{V}$ data by a sine series of relative wind direction $(\varphi)$ for each wind speed (w) [11].

$\mathrm{U}(\mathrm{w}, \varphi)=\Sigma \mathrm{U}_{\mathrm{n}}(\mathrm{w}) \sin (\mathrm{n} \varphi)$

$\mathrm{V}(\mathrm{w}, \varphi)=\Sigma \mathrm{V}_{\mathrm{n}}(\mathrm{w}) \sin (\mathrm{n} \varphi)$

Here $n=1$ to $N$. We varied the number of terms $(N)$ for the sine series to fit the binned data and calculated the residual 

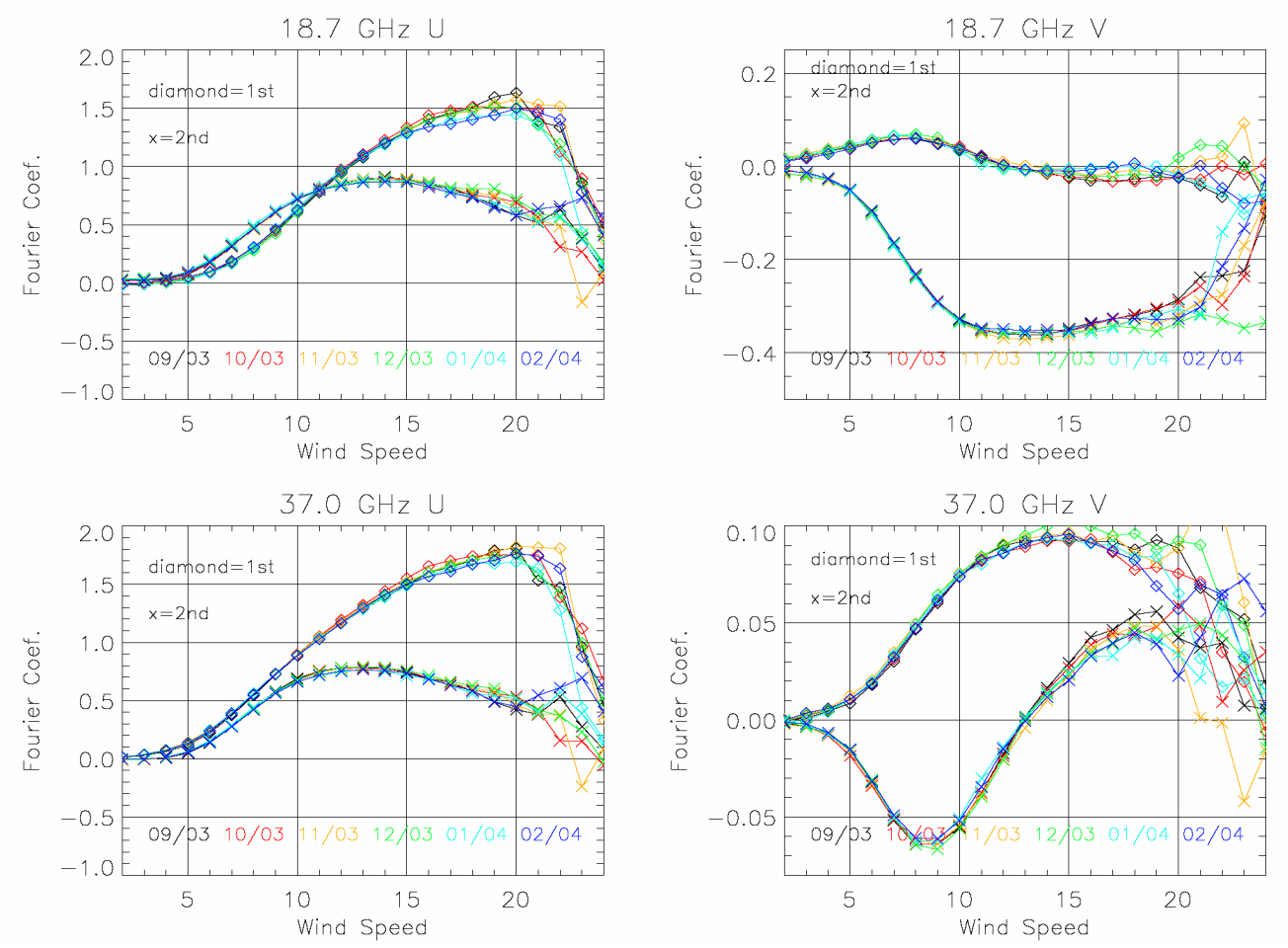

Figure 1. The first and second coefficients of sine series for the WINDSAT 18 and $37 \mathrm{GHz} \mathrm{U}$ and V channels, The coefficients for each month of data from September 2003 to February 2004 are illustrated. The difference is less than $0.1 \mathrm{~K}$ for wind speed $<20 \mathrm{~m} / \mathrm{s}$.

errors. We found that a four-term sine series is sufficient to fit the data to better than $0.1 \mathrm{~K}$ accuracy.

Figure 1 illustrates the first and second sine series coefficients for $\mathrm{U}$ and $\mathrm{V}$ versus wind speed. The coefficients were derived from each month of WINDSAT and GDAS match-up data. The first harmonic coefficients $\left(\mathrm{U}_{1}\right)$ at 18 and $37 \mathrm{GHz}$ increase with increasing wind speed for up to about 20 $\mathrm{m} / \mathrm{s}$. The second harmonic coefficients $\left(U_{2}\right)$, having a different feature, increase with wind speed from light to moderately high wind speed $(<15 \mathrm{~m} / \mathrm{s})$ and then display a decreasing trend beyond about $15 \mathrm{~m} / \mathrm{s}$ wind speed. The deviation of coefficients from month to month is small $(<0.1 \mathrm{~K})$, except for $>20 \mathrm{~m} / \mathrm{s}$ wind speed. Averaging over six months of data seems necessary to achieve adequate number of samples to improve the estimate of model coefficients for up to $23-24 \mathrm{~m} / \mathrm{s}$ (Fig. 2).

Here is the summary of our preliminary findings from the analysis of six months of data.

1. The characteristics of $U_{n}$ coefficients are very similar at 18 and $37 \mathrm{GHz}$ frequencies. However, the $37 \mathrm{GHz} \mathrm{U}_{1}$ appears to be about 20 percent stronger than the $18 \mathrm{GHz}$ data.

2. The $18 \mathrm{GHz} \mathrm{V}$ data show negligible first harmonic coefficients and are dominated by the second harmonics. The amplitude of $18 \mathrm{GHz} \mathrm{V}_{2}$ reaches to about $0.4 \mathrm{~K}$ at 10 $\mathrm{m} / \mathrm{s}$ and gently decreases with wind speed.

3. The directional signature of WINDSAT data agrees very well with the JPL aircraft polarimetric wind radiometer
(WINDRAD) measurements acquired in 1990s and 2003 for WINDSAT CAL/VAL (Figure 3).

4. What is unexpected from the WINDSAT V measurements is the strikingly distinct features between 18 and $37 \mathrm{GHz}$ frequencies. The $37 \mathrm{GHz} \mathrm{V}$ data display very small wind direction harmonics, unlike the $18 \mathrm{GHz}$ data. This is different from the predictions of the state-of-art physical scattering models of sea surfaces $[10,11]$, which predict similar V signals for 18 and $37 \mathrm{GHz}$. Should the WINDSAT observations be right, new scattering physics have to be investigated to understand the air-sea interaction processes. Furthermore if the WINDSAT 37 $\mathrm{GHz} \mathrm{V}$ data are valid, then there is very little value to include the circular polarization measurement capability into the National Polar Orbiting Environmental Satellite System (NPOESS) Conical Microwave Imaging system (CMIS) design.

\section{MODEL VALIDATION}

To facilitate the Windsat calibration and geophysical model function development, we conducted two NASA DC-8 aircraft underflights for Windsat in June 2003. Deployed on the DC-8 included the polarimetric $\mathrm{K}$ - and $\mathrm{Ka}$-band wind radiometers (WINDRAD) and a polarimetric Ku-band scatterometer (POLSCAT) [12] developed by the Jet Propulsion Laboratory. The aircraft flights were coordinated with the Windsat passes over the NDBC buoy in the Pacific Ocean $660 \mathrm{~km}$ West of San Francisco. The buoy winds 

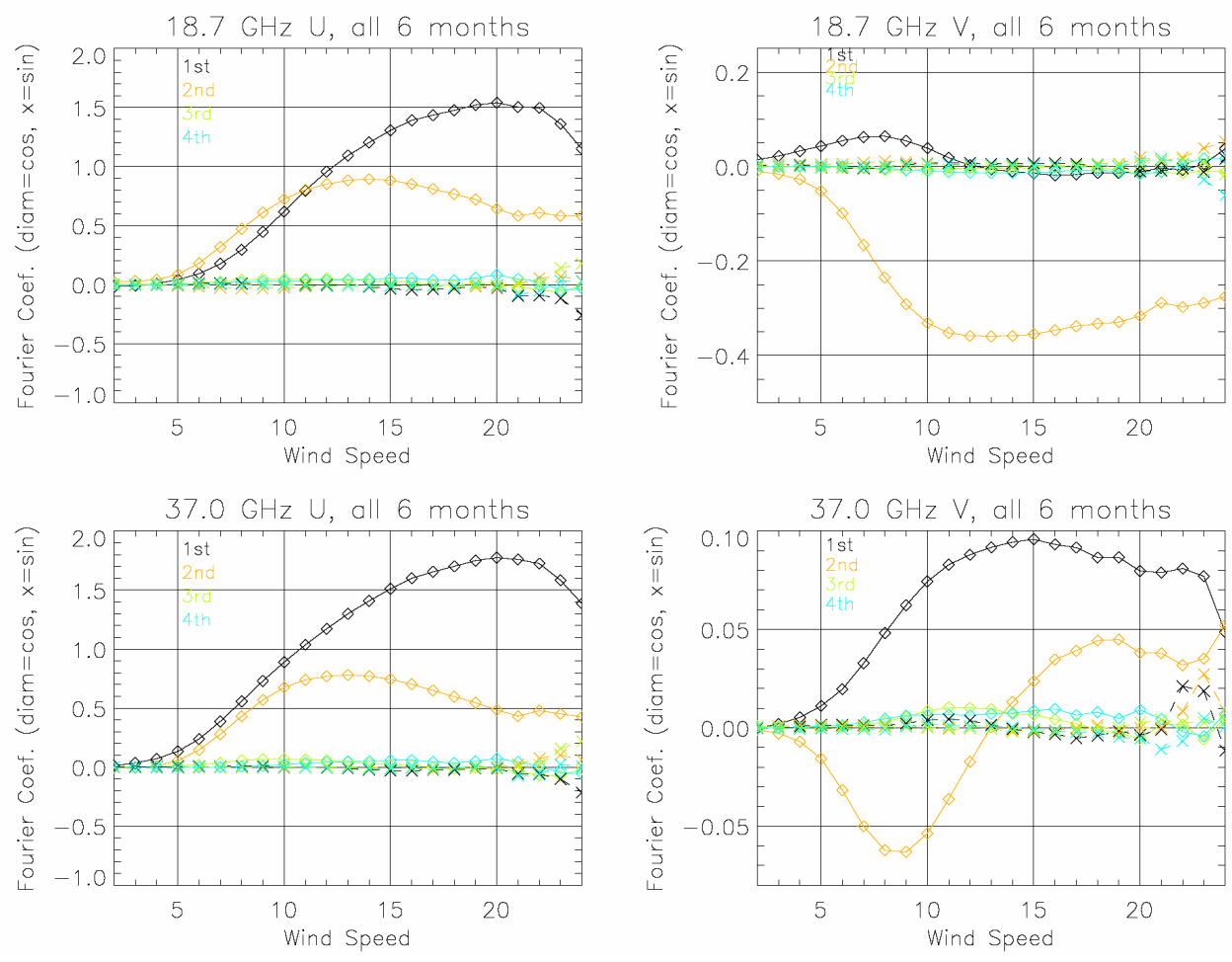

Figure 2. The first and second coefficients of sine series for the WINDSAT 18 and $37 \mathrm{GHz} \mathrm{U}$ and V channels, The coefficients are derived from six months of data from September 2003 to February 2004.

showed excellent agreement with those derived from POLSCAT and the SeaWinds scatterometers. Comparison of the aircraft WINDRAD data with the Windsat observations indicates that the absolute calibration for Windsat fore-look data is excellent (within 1-2 K).

We collocated the winds from the SeaWinds scatterometer on the QuikSCAT spacecraft with the two revs of Windsat data, corresponding to the aircraft flights. There were about 70,000 collocations for wind speed in the range of $1-14 \mathrm{~m} / \mathrm{s}$. The SeaWinds winds were used to simulate the Windsat observations from the WINDRAD geophysical model function. The model simulations are in good agreement (within 20\%) for the third Stokes parameter from 3-12 m/s wind speeds.

\section{SUMMARY}

We have analyzed six months of Windsat data and derived the geophysical model function for the Windsat polarimetric channels. The model function coefficients do not seem to have significant variations from month to month for up to $20 \mathrm{~m} / \mathrm{s}$ wind speed. The Windsat GMF also has a very good agreement with the JPL WINDRAD observations acquired over 1993-2003 and the scatterometer winds from SeaWinds and POLSCAT.

\section{ACKNOWLEDGMENT}

The research carried out in this paper is performed by the Jet Propulsion Laboratory under a contract with the National Aeronautics and Space Administration. The work was funded by the National Polar Orbiting Environmental Satellite System.

\section{REFERENCES}

[1] V. S. Etkin, M.D. Raev, M.G. Bulatov, Yu.A. Militsky, A.V. Smirnov, V.Yu. Raizer, Yu.A. Trokhimovsky, V.G. Irisov, A.V. Kuzmin, K.Ts. Litovchenko, E.A. Bespalova, E.I. Skvortsov, M.N. Pospelov, and A.I. Smirnov, Radiohydrophysical Aerospace Research of Ocean, Report $\pi \mathrm{p}-1749$, Academy of Sciences, Space Research Institute, Moscow, USSR, 1991.

[2] V. G. Irisov, A. V. Kuzmin, M. N. Pospelov, J. G. Trokhimovsky, and V. S. Etkin, "The dependence of sea brightness temperature on surface wind direction and speed. Theory and Experiment.," IEEE, Proceedings of International Geoscience and Remote Sensing Symposium, pp.12971300, Espoo, Finland, 1991.

[3] S. H. Yueh, W. J. Wilson, F. K. Li, W. B. Ricketts, and S. V. Nghiem, "Polarimetric measurements of sea surface brightness temperatures using an aircraft K-band radiometer," IEEE Trans. Geosci. Remote Sensing, Vol. 33, No. 1, 85-92, 1995.

[4] S. H. Yueh, W. J. Wilson, F. K. Li, W. B. Ricketts, and S. V. Nghiem, "Polarimetric brightness temperatures of sea surfaces measured with aircraft K- and Ka-band radiometers," IEEE Trans. Geosci. Remote Sensing, Vol. 35, No. 5, 1997.

[5] S. H. Yueh, W. J. Wilson, S. Dinardo, and F. K. Li, "Polarimetric microwave brightness signatures of ocean wind directions," IEEE Trans. Geosci. Remote Sensing, Vol. 37, No. 2, 1999.

[6] J. R. Piepmeier and A. J. Gasiewski, "High-resolution passive polarimetric microwave mapping of ocean surface wind vector fields," IEEE Trans. Geosci Remote Sensing, Vol. 39, No. 3, pp. 606-622, Mar 2001. 

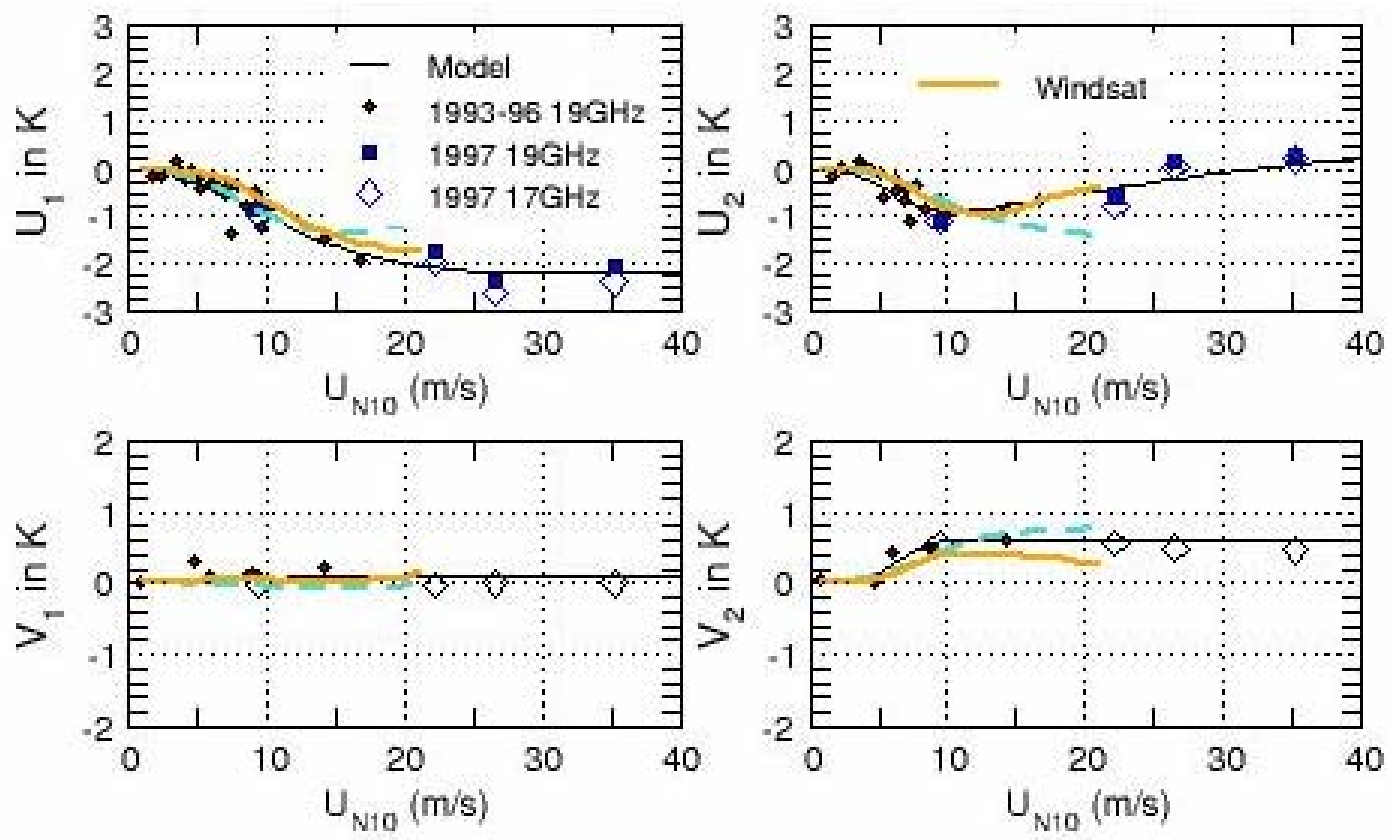

Figure 3. Comparison of $18 \mathrm{GHz}$ Windsat $\mathrm{U}$ and $\mathrm{V}$ sine series coefficients with the JPL aircraft polarimetric WINDRAD data acquired from 1993-1997. Orange curves for WINDSAT data and symbols for aircraft

WINDRAD data. Note that the sign of Windsat $\mathrm{U}$ and $\mathrm{V}$ estimates are changed to use the same definition with JPL WINDRAD.

[7] B. Laursen and N. Skou, "Wind direction over the ocean determined by an airborne, imaging, polarimetric radiometer system," IEEE Trans. Geosci Remote Sens., Vol. 39, No. 7, pp. 1547-1555, July 2001.

[8] J. Lahtinen, J. Pihlflyckt, K. Mononen, S. J. Tauriainen, M. Kemppinen, and M. T. Hallikainen, "Fully polarimetric microwave radiometer for remote sensing, "IEEE Trans. Geosci. Remote Sens., Vol. 41, No. 8, pp. 1869-1878, August 2003.

[9] S. H. Yueh, "Modelling of Wind Direction Signals in Polarimetric Sea Surface Brightness Temperatures," IEEE Trans. Geosci. Remote Sensing, Vol. 35, No. 6, 1400-1418, November 1997.
[10] K. St. Germain and G. Poe, "Modeling of the Polarimetric Microwave Signal due to Ocean Surface Wind Vector," Proc. of 6th Specialist Meeting on Microwave Radiometry and Remote Sensing of the Environment, p.71, March 1999, Florence Italy.

[11] S. H. Yueh, R. Kwok, and S. V. Nghiem, "Polarimetric scattering and emission properties of targets with reflection symmetry," Radio Science, Vol. 29, No. 6, 1409-1420, November-December, 1994.

[12] S. H. Yueh, W. J. Wilson, and S. Dinardo, "Polarimetric Radar Remote Sensing of Ocean Surface Wind," IEEE Trans. Geosci. Remote Sens., 40, 793-800, April 2002. 